\title{
Soil Inorganic Carbon Research Progress in China
}

\author{
XIONG YuFei ${ }^{1,2,3,4, a}$ \\ ${ }^{1}$ Shaanxi Provincial Land and Engineering Construction Group Co., Ltd. Xi'an 710075, China \\ ${ }^{2}$ Institute of Land Engineering and Technology, Shaanxi Provincial Land Engineering Construction \\ Group Co., Ltd. Xi'an 710075, China \\ ${ }^{3}$ Key Laboratory of Degraded and Unused Land Consolidation Engineering, the Ministry of Land \\ and Resources of China, Xi'an 710075, China \\ ${ }^{4}$ Shaanxi Provincial Land Consolidation Engineering Technology Research Center. Xi'an 710075, \\ China; \\ axiongyf1991@163.com.
}

Keywords: Global change, soil carbon pool, soil inorganic carbon, carbon recycle

Abstract: Inorganic carbon comprises approximately a third of the total $\mathrm{C}$ pool in soils worldwide, largely in the form of pedogenic calcite. Most of the SIC pool is located in arid and semi-arid regions of the world and accumulates as subsurface concentrations of carbonate minerals, predominantly calcite (CaCO3), as the result of minimal leaching through the soil column. The content of SIC is affected by many reasons, climate and land use types are the two major factors. Moreover, human activities play more and more important role in carbon cycle. Understanding the processes governing the storage and flux of this inorganic $\mathrm{C}$ pool is crucial to the development of accurate regional and global $\mathrm{C}$ budgets.

\section{Introduction}

With the increasing of the interest in research of global change, soil carbon pool has been one of the hot pints in the global carbon cycle. Soils hold the largest terrestrial carbon pool and may be an active participant in short-term net $\mathrm{CO}_{2}$ fluxes(Mielnick et al., 2005). IPCC pointed out that the global average temperatures have been increasing since the mid-20th century, which is very likely due to the observed increase in anthropogenic greenhouse gas concentrations (Huang et al., 2010) . The role of soil carbon in the greenhouse effect has received considerable attention (Wu et al., 2009) .

The soil carbon pool has two principal components: soil organic carbon (SOC) and soil inorganic carbon (SIC). In order to know the mechanism of carbon recycle, both organic and inorganic carbon pools need to be considered (Mi et al., 2008).

The SIC pool can be classified as lithogenic inorganic C (LIC) and pedogenic inorganic C (PIC). The former is inherited from parent material, with no change in soil inorganic carbon. The latter is formed through the dissolution and re-precipitation of carbonate parent material (Wu et al., 2009).

According to Pan(1999), soil inorganic carbon including $\mathrm{HCO}^{3^{-}}$in the soil solution, $\mathrm{CO}_{2}$ in the soil air and deposition in the soil of calcium carbonate $\left(\mathrm{CaCO}_{3}\right)$. Carbonates play an important 
role in the global $\mathrm{C}$ cycle with the following pedospheric interactions: (I) exchange between atmosphere, ocean, and terrestrial carbon pools and (ii) carbon sequestration in soil through the formation of secondary carbonates(Mikhailova and Post, 2006). Accordingly, carbon dynamics in carbonate-dominated rivers is important to our understanding of global and regional carbon cycles on a short-term scale(Li et al., 2010).

\section{Distribution of SIC across China}

In general, SIC contents in China increased from east to west and decreased from north to south (Fig.1). SIC contents were the highest, ranging from 12.0 to $25.0 \mathrm{~kg} \mathrm{C} \mathrm{m}^{-2}$, in loessial soils (Calcaric Regosols) and Castano-cinnamon soils (Kastanozems) in northern China while SIC contents were generally less than $1.0 \mathrm{~kg} \mathrm{C} \mathrm{m}^{-2}$ in tropical and subtropical soils in southern China(Wu et al., 2009).

SIC contents generally increase in correspondence with the increase of aridity from east to west and from south to north. The lowest SIC contents found in southern and northeastern China where strong carbonate leaching under humid climatic conditions is not in favor to its precipitation. The highest SIC contents, found in the Loess Plateau region, are also associated with the primary eolian deposit $\mathrm{CaCO}_{3}$ source, containing high amounts of $\mathrm{CaCO}_{3}(\sim 10 \%)$ in dust transported from desert regions in northern China (Wu et al., 2009).

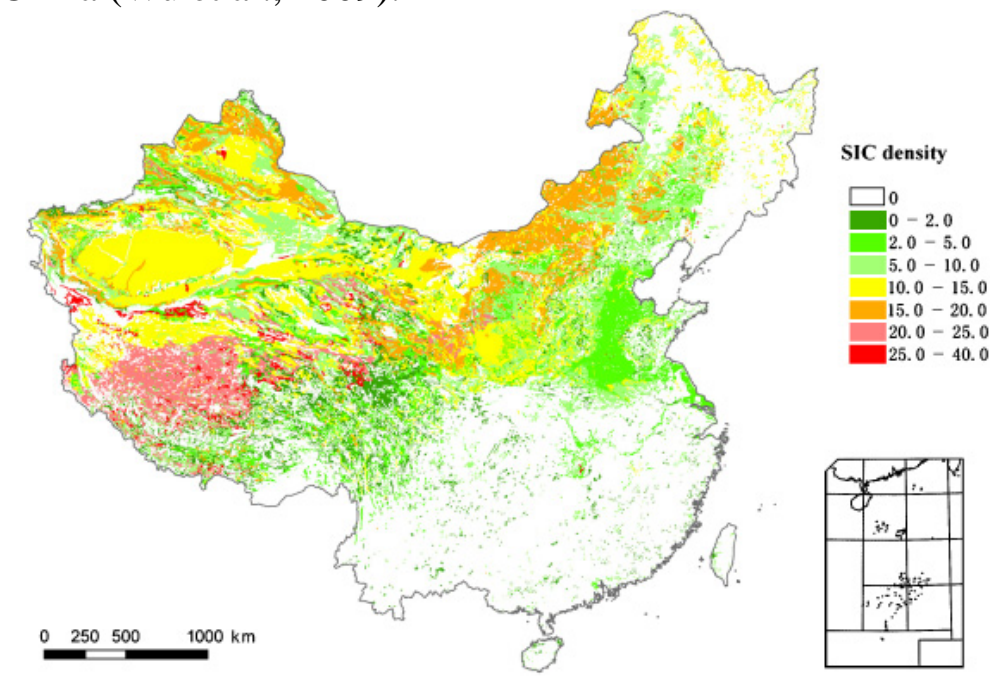

Fig. 1 Spatial pattern of SIC content in China (units $\mathrm{kg} \cdot \mathrm{m}-3$ ). Representation of the average SIC contents of each soil subgroup. In China, the whole number of soil subgroups is 277 according to soil taxonomy; among them the number of soil subgroups with carbonates data is 125 based on soil profile database of second national soil survey(Mi et al., 2008)

\section{Main Influence factors}

\subsection{Climate}

Soil data employed in many studies were based on the second national soil survey (SNSS) of China conducted from 1979 to 1992. Mi et al.(2008) excluded profiles without measured carbonate data, grouped the remaining soil profiles based on location (e.g. longitude, latitude and elevation), soil type and vegetation coverage, and extracted SOC and SIC information of different climate gradients by overlaying SIC and SOC grids with mean annual temperature (MAT) and mean annual precipitation (MAP) grids in ARCGIS. The conclusions is that the SIC content showed a stronger positive correlation with evaporation than did with other variables and also had positive and 
negative correlation with MAT and MAP, respectively.

Wang et al.(2004) did some research on vertical distribution, their results indicate that SOC decreases with increasing MAT and increases with increasing precipitation based on correlation analyses. They also find that soil in the upper $20 \mathrm{~cm}$ stores about $40 \%$ of total SOC to a depth of $100 \mathrm{~cm}$.

According to some early studies(Z.Liu, 1999), the SIC pool is mainly concentrated in soils of arid and semiarid eco-regions with annual precipitation $<500 \mathrm{~mm}$. The content of SIC showed a positive correlation with elevation and a negative one with MAP for investigated profiles, The positive correlation between elevation and SIC content is attributed to the decreasing MAP and MAT with increasing elevation(Mi et al., 2008).

To further evaluate the effects of climatic parameters on SIC storage, the soil profiles were divided into groups in climatic ranges. Within each MAT gradient $\left(-10\right.$ to $0^{\circ} \mathrm{C}$ for cold temperate, 0 $10^{\circ} \mathrm{C}$ for warm temperate, $10-20^{\circ} \mathrm{C}$ for subtropics, $20-30^{\circ} \mathrm{C}$ for tropic), MAP was divided into five ranges. The result shows that MAP has larger influence on SIC formation and spatial distribution than MAT.(Mi et al., 2008)

\subsection{Land use types}

An experiment was done by Mikhailova and Post in Russian Chernozem, four sites were sampled: a native grassland field (not cultivated for at least $300 \mathrm{a}$ ), an adjacent 50 years continuous fallow field, a yearly cut hay field in the V.V. Alekhin Central-Chernozem Biosphere State Reserve in the Kursk region of Russia, and a continuously cropped field in the Experimental Station of the Kursk Institute of Agronomy and Soil Erosion Control, the SIC stocks in the top 2m were 107Mg/ha, $196 \mathrm{Mg} / \mathrm{ha}, 91 \mathrm{Mg} / \mathrm{ha}$ and $242 \mathrm{Mg} / \mathrm{ha}$, respectively(Mikhailova and Post, 2006). Their results show that:fertilizer and manure additions (which contain $\mathrm{Ca}^{2+}$ necessary for carbonate formation) may be the explanation to the cropping field. The soil organic $C$ stocks significantly decrease as a result of cultivation while the SIC stocks significantly increase (Mikhailova and Post, 2006).Ghosh (2010) concluded that fertilizer application and especially manure application have the potential to significantly increase SOC in agricultural soils.The magnitude of SIC content for different land covers is in the following order of magnitude: desert $>$ grassland $>$ cropland $>$ marsh $>$ shrub land $>$ meadow $>$ forest.Land cover type has a strong influence on the vertical distribution of roots and SOC and these imprints are likely to affect SIC distribution(Mi et al., 2008).(Fig.2).
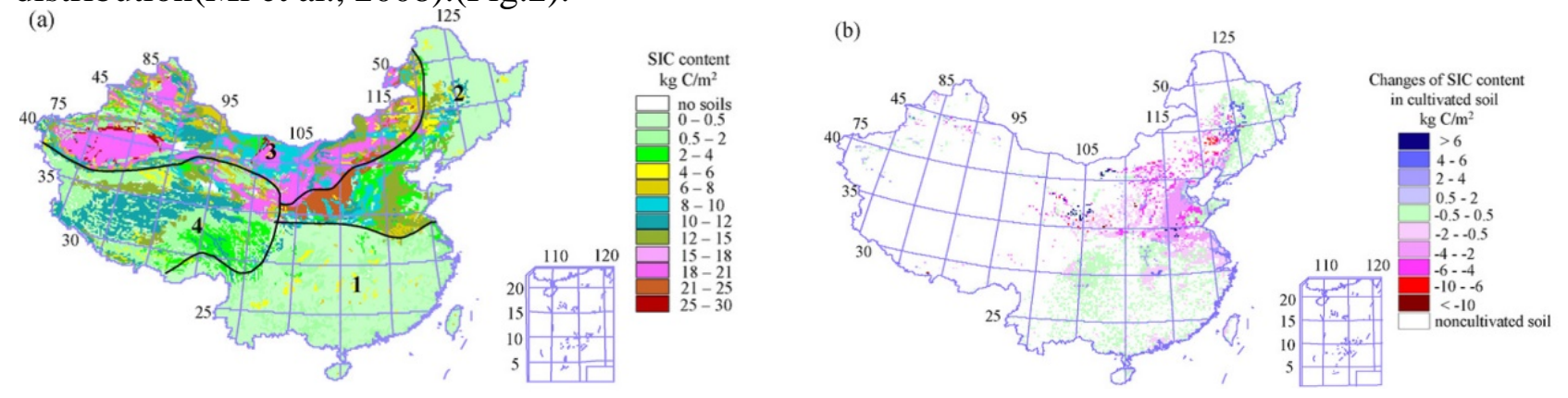


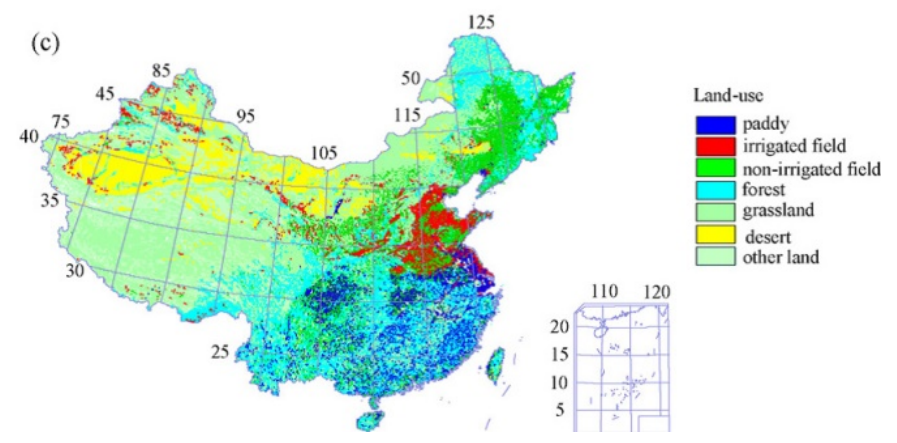

Fig.2 Spatial distribution of soil inorganic carbon (SIC) contents and the changes in SIC content and land use activity in China. (a) Distribution in SIC content under present-day conditions; (b) distribution of SIC content changes; and (c) distribution of land use activity. The four major climatic zones shown in (a) refer to the monsoonal tropical-subtropical zone (Zone 1), the monsoonal temperate zone (Zone 2), the arid zone in northwestern China (Zone 3), and the frigid zone in the Tibetan Plateau region (Zone 4), respectively.

Changes in SIC contents throughout cultivated soils in China due to historical land use activity was calculated by comparing the differences in SIC content under non-cultivated and cultivated conditions in the same subgroups. Overall, approximately $51 \%$ of the total cultivated soil area experienced SIC loss.Most C loss occurred in cultivated soils that include irrigated fields, dry farmland, and paddy fields(Wu et al., 2009).

SIC loss in these areas may be attributed to irrigation practices that increase carbonate leaching in soil profile, particularly in the presence of acidifying fertilizers that increase nitrogen and sulphur inputs. The loss may also be attributed to agricultural practices that expose the calciferous horizon to the soil surface, increasing carbonate weathering and erosion(Wu et al., 2009).

On the other hand, an obvious SIC increase was observed in approximately $10 \%$ of the total cultivated surfaces. A comparison of the soil carbon density between unused and agricultural lands in Heilongjiang revealed that the average carbon density in the unused land was 2.4,2.3 and 3.0 times that of the agricultural lands, respectively (Xiaohua $\mathrm{Xi}, 2011$ ). The SIC increase is probably due to irrigation that leads to a dramatic increase in biomass production. This should result in increased plant respiration and microbial decomposition of organic matter and thus lead to increased soil $\mathrm{CO}_{2}$ levels (Wu et al., 2009). But, in fact, atmospheric $\mathrm{CO}_{2}$ could also be consumed where carbonate rock weathering occurred due to the high humidity in these areas.

Compared with SIC change in China, A significant SOC loss was observed within a belt from northeast to southwest China, mainly in non-irrigated soils under semiarid and semi-humid conditions with the maximum SOC loss in northeast China. In contract, the paddy soils in southern China and some irrigated soils in northwest China showed a net gain in SOC. No significant changes were observed in other irrigated soils in eastern China. Therefore, the impacts of agricultural land use on SIC and SOC pools in soils were different. For the SOC, the C loss means it is the source of atmospheric $\mathrm{CO}_{2}$. While for the SIC, if the loss of leached carbonate remains in the lower soil profile or resides in river systems, groundwater, or oceans for a 100 years or more.

\section{Conclusions}

Based on the latest available soil profile data investigated by China's second national soil survey and some research, we can know that :

(1) The SIC contents were higher from east to west and from south to north, and the highest in 
arid regions;

(2) The amount of SIC was related to climate ,content of SIC was positively related with MAT and negatively related with MAP;

(3) Land use type was an important facts, human activity such as cultivation, irrigation, fertilization, has significantly affected the SIC pool that plays an important role in the global C cycle;

(4) The relation between SIC and SOC was not very clear, a better and integrated understanding of SOC and SIC changes in soils will be critical.

\section{References}

[1] Ghosh, S., 2010. <Changes in soil organic carbon pool in three long-term fertility experiments with different cropping systems and inorganic and organic soil amendments in the eastern cereal belt of India.pdf $>$.

[2] Huang, Y., Sun, W., Zhang, W., Yu, Y., 2010. Changes in soil organic carbon of terrestrial ecosystems in China: a mini-review. Science China. Life sciences 53, 766-775.

[3] Li, S.-L., Liu, C.-Q., Li, J., Lang, Y.-C., Ding, H., Li, L., 2010. Geochemistry of dissolved inorganic carbon and carbonate weathering in a small typical karstic catchment of Southwest China: Isotopic and chemical constraints. Chemical Geology 277, 301-309.

[4] Mi, N.A., Wang, S., Liu, J., Yu, G., Zhang, W., JobbÁGy, E., 2008. Soil inorganic carbon storage pattern in China. Global Change Biology 14, 2380-2387.

[5] Mielnick, P., Dugas, W.A., Mitchell, K., Havstad, K., 2005. Long-term measurements of CO2 flux and evapotranspiration in a Chihuahuan desert grassland. Journal of Arid Environments 60, 423-436.

[6] Mikhailova, E.A., Post, C.J., 2006. Effects of land use on soil inorganic carbon stocks in the Russian Chernozem. Journal of environmental quality $35,1384-1388$.

[7] Wang, S., Huang, M., Shao, X., Mickler, R.A., Li, K., Ji, J., 2004. Vertical Distribution of Soil Organic Carbon in China. Environmental Management 33.

[8] Wu, H., Guo, Z., Gao, Q., Peng, C., 2009. Distribution of soil inorganic carbon storage and its changes due to agricultural land use activity in China. Agriculture, Ecosystems \& Environment 129, 413-421.

[9] Xiaohua Xi, Z.Y., 2011. <A study of soil organic carbon distribution and storage in the northeast plain of China.pdf>.

[10] Z.Liu, J.Z., 1999. <Contribution of carbonate rock weathering to the atmospheric CO2 sink.pdf> . 